\title{
Potential role of interferon-lambda in the treatment of inflammation and cancer: an update
}

This article was published in the following Dove Press journal:

International Journal of Interferon, Cytokine and Mediator Research

30 June 2011

Number of times this article has been viewed

\author{
Heike Dornhoff \\ Jürgen Siebler \\ Markus F Neurath \\ Department of Medicine, \\ University of Nuremberg-Erlangen, \\ Erlangen, Germany
}

Correspondence: Markus F Neurath Professor of Medicine, Medical Clinic I, Friedrich-Alexander-Universität Erlangen-Nürnberg, Ulmenweg 18 , D-91054 Erlangen, Germany

Tel +9l 3I 8535000

Fax +91 31 8535209

Email markus.neurath@uk-erlangen.de

\begin{abstract}
The interferon (IFN) family comprises various cytokines with potent responses against RNA and DNA viruses as well as antitumor activities. A recently identified interferon subgroup consists of the so-called lambda interferons with several members, including IFN- $\lambda 1$, IFN- $\lambda 2$, and IFN- $\lambda 3$ (also denoted interleukin [IL]-29, IL28-A, and IL28-B). They represent a newly identified group of the class II cytokine family. While they are functionally related to type I IFNs, they are structurally related to the IL-10 cytokine family. The lambda IFNs signal through a cytokine receptor complex which is unique for IL-28 and IL-29, designated IL-28R $\alpha$, and a second chain, the IL-10R2, which is shared with receptors for IL-10 related cytokines such as IL-22 and IL-10. In this review, we summarize recent findings about the relationship between type I and type III IFN signaling as well as their antiviral and antitumor activity. A better understanding of the functional role of IFN- $\lambda$ in viral infections and immune responses in innate and adaptive immunity opens new therapeutical approaches for the treatment of chronic inflammatory diseases and cancer.
\end{abstract}

Keywords: interferon, interleukin-28, cancer, viral infections, antiviral, antitumor, immunity

\section{Introduction}

Interferon (IFN) was first identified in the late 1950s (1957) by Isaacs and Lindemann. ${ }^{1}$ They found that IFN production was induced by virus-infected chicken embryo cells and that IFN functions as inhibitor of viral replication. For a long time IFNs were thought to have an impact only in virus infection but later on it was shown that they have also proinflammatory effects and this is especially true for the IFN $\gamma$ cytokine. IFNs such as IFN- $\alpha$, IFN- $\beta$, and IFN- $\gamma$ may act on innate immune cells as well as on the adaptive immune system. Innate immunity relates to the first barrier defense against invading pathogens, and one of the first responses of virally infected organisms consists of the secretion of IFNs. Studies in mice have shown that insensitivity towards IFNs results in impaired capacity to sustain viral defense and to control viral infections. ${ }^{2-4}$ The relevance of these findings is highlighted by studies in patients showing that dysfunctions in IFN expression and/or signaling cause a high prevalence of viral infections. Additionally, the IFN pathways are also activated in multiple diseases like systemic lupus erythematosus, rheumatoid arthritis, and systemic sclerosis, ${ }^{5}$ underscoring the potential relevance of treating inflammatory diseases by modulating IFN function. Indeed, the clinical use of IFNs was started in the 1980s for the treatment of viral diseases, multiple sclerosis, and cancer. ${ }^{6}$

In addition to the known groups of IFNs, a novel group of IFNs was recently discovered independently by two groups: Kotenko and Gallagher ${ }^{7}$ and a group 
around Klucher and coworkers. ${ }^{8}$ They identified from human genomic sequences a family of three cytokines, designated interleukin-28A (IL-28A), IL-28B, and IL-29, also called IFN- $\lambda 2$, IFN- $\lambda 3$, and IFN- $\lambda 1$. Based on these findings, IFNs can now be classified into three different types, which share similar properties, amino acid sequences, and structural motifs (Table 1). Functionally, IFN- $\lambda$ s are related to type I IFNs. Structurally, they are related to the IL-10 superfamily and are now referred to as type III IFNs. ${ }^{7}$ Whereas IL-29 is present in humans, in mice it is encoded by a pseudogene and therefore not functionally active.

\section{The IFN family and their signaling pathways}

Type I IFNs are a homologous cytokine family whose genes are located on chromosome 9. They are mostly nonglycosylated proteins of 165 to 200 amino acids that share $30 \%$ to $85 \%$ homology within a species. Type I IFNs binds on cell-surface receptors composed of two ubiquitously expressed transmembrane proteins, IFN receptor 1 (IFNAR1) and IFNAR2. The signaling is dependent on the association of two cytoplasmic tyrosine kinases, TYK2 and the Janus tyrosine kinase (JAK) 1 (Figure 1). After ligand binding the signal transducers and activators of transcription (STATs) become phosphorylated, form heterodimers together with IFN regulatory factor 9 (IRF9) to build the heterotrimeric complex IFN-stimulated gene factor (ISGF3), and translocate to the nucleus to activate the transcription of antiviral genes. ${ }^{9-11}$ Type I IFNs can be expressed by almost every cell type. However, it should be noted that humans have 13 functionally active IFN- $\alpha$ molecules expressed predominantly by leucocytes and one IFN- $\beta$ molecule produced by fibroblasts and plasmocytoid dendritic cells, and to a lesser extent IFN- $\omega$, IFN- $\varepsilon$, and IFN- $\kappa$. There is only one type II IFN, namely IFN- $\gamma$. This type of IFN is mainly produced by natural killer $(\mathrm{NK})$ and $\mathrm{T}$ cells and signals through a distinct heterodimer of two membrane spanning receptors, IFN- $\gamma \mathrm{R} 1$ and IFN- $\gamma \mathrm{R} 2$. The former receptor is constitutively expressed on all cell types, whereas the latter receptor is tightly regulated and expressed on few cell types only (eg, T lymphocytes). In T cells, the receptor is capable of recruiting STAT1 on activation, leading to STAT1 phosphorylation and translocation in the nucleus. ${ }^{12-16}$ Finally, the key transcription factor T-bet becomes activated, leading to IL-12Rbeta 2 chain expression and subsequent Th1 T cell differentiation.

Finally, an IFN family distinct from type I IFNs are the type III IFNs. They are also called lambda IFNs and consist of three subtypes: IFN- $\lambda 1$, IFN- $\lambda 2$, and IFN- $\lambda 3$. They activate the same signaling pathway as do type I IFNs but act by binding to a different receptor complex. Together with IRF9, STAT1 and STAT2 form then a trimeric complex, ISGF3, that drives transcription of IFN-stimulated genes for antiviral activity. ${ }^{17}$ The IFN- $\lambda$ receptor is composed of two membrane spanning proteins, IFNLR1 and IL-10R2. ${ }^{18}$ Whereas IFNARs are expressed ubiquitiously, IFNLR1 (IL-28R $\alpha$ ) is expressed on only few cell types, especially on epithelial cells. ${ }^{7,8,19}$ The different expression of type I versus type III receptors is a key difference between these types of IFNs. This appears to be the main reason for the different biological activities of these functionally related cytokines with antiviral response in vivo. The major parts of the interferon signaling cascade are mediated via STATs and JAKs. All three receptor types of the IFN signaling pathways are associated with the binding of JAK family members. After ligand binding they become activated and then phosphorylated. After that dimers are formed that transduce signals to the nucleus where target structures like ISRE (IFN stimulated response element) and GAS (IFN- $\lambda$ activated sequence) are activated.

\section{Regulation of IFN- $\lambda$ gene expression and cellular targets}

The production of IFNs is induced by stimulation with various viruses including RNA and DNA viruses, protozoa, and microbial products or by chemical inducers. ${ }^{20}$ Similarly to

Table I The interferons and their subclasses

\begin{tabular}{|c|c|c|c|c|c|}
\hline Class & Subclass & Genes & Receptor & Cell types & Function \\
\hline I & $\begin{array}{l}\alpha \\
\beta \\
\varepsilon, \kappa, \omega\end{array}$ & $\begin{array}{l}\text { I } 7 \text { but } 13 \text { only } \\
\text { functional in human }\end{array}$ & $\begin{array}{l}\text { IFNARI } \\
\text { IFNAR2 }\end{array}$ & $\begin{array}{l}\text { NK/CD8+ } \\
\text { DC } \\
\text { B-cells }\end{array}$ & $\begin{array}{l}\text { Cytotoxicity, THI, survival, antiviral, antitumor, } \\
\text { proapoptotic, antiproliferative effects }\end{array}$ \\
\hline II & $\gamma$ & IFN- $\gamma$ & $\begin{array}{l}\text { IFNGRI } \\
\text { IFNGR2 }\end{array}$ & $\begin{array}{l}\text { NK/T cells } \\
\text { Macrophages }\end{array}$ & THI, immune responses, antitumor effects \\
\hline III & $\lambda$ & $\begin{array}{l}\text { IL-28A } \\
\text { IL-28B } \\
\text { IL-29 (mouse: pseudogene) }\end{array}$ & $\begin{array}{l}\text { IFNLRI } \\
\text { IL-IOR2 }\end{array}$ & $\begin{array}{l}\text { Epithelial cells } \\
\text { Hepatocytes } \\
\text { pDC/keratinocytes }\end{array}$ & $\begin{array}{l}\text { Antiviral, antitumor, pro- and antiapoptotic, } \\
\text { antiproliferative effects, immune regulation }\end{array}$ \\
\hline
\end{tabular}

Abbreviations: DC, dendritic cells; pDC, plasmacytoid DC; IFN, interferon; IL, interleukin; NK, natural killer; TH, T helper. 


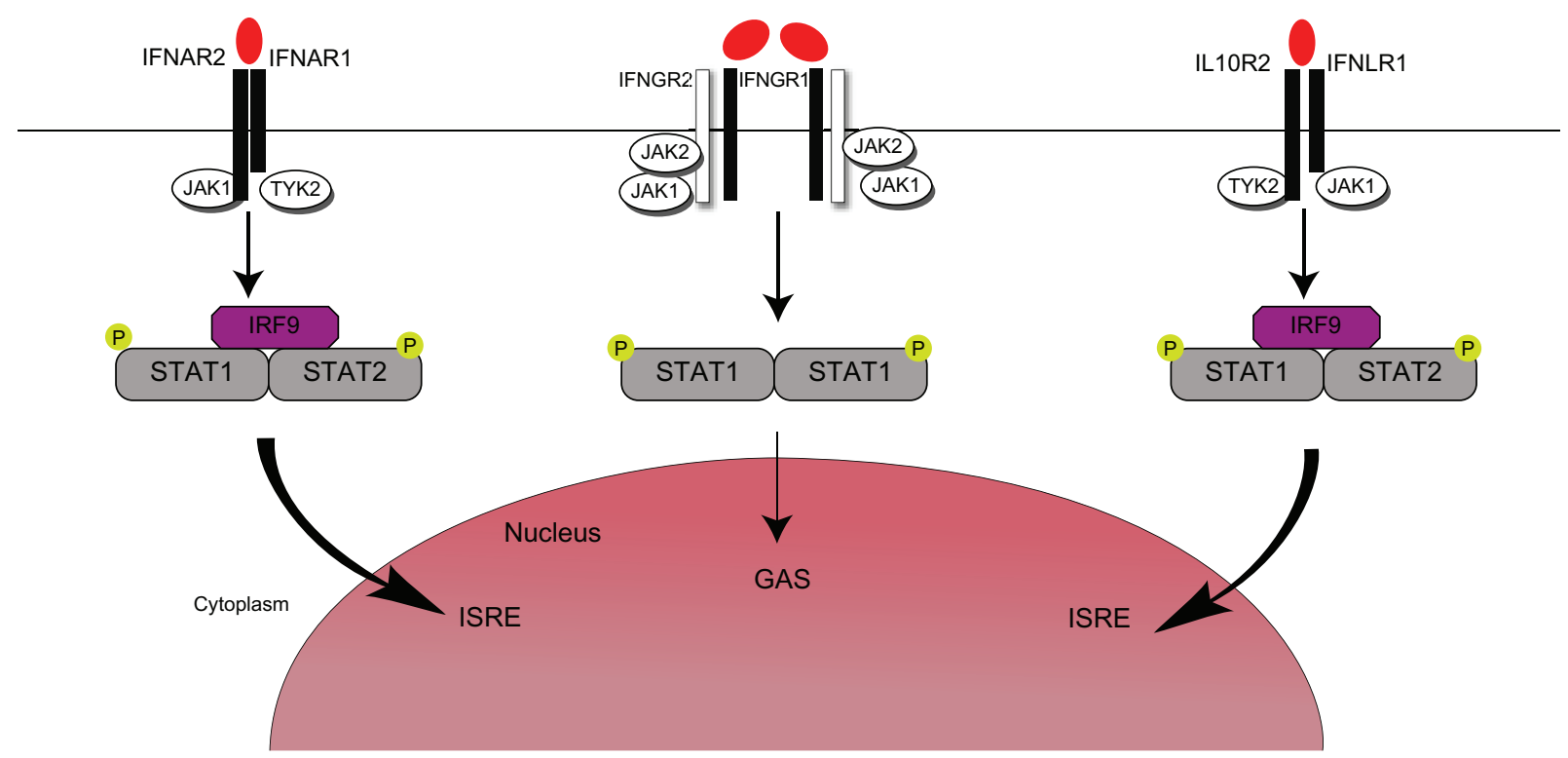

Figure I Interferon signaling. Schematic presentation of receptor complexes, intracellular JAK/STAT signaling, and antiviral gene activation for all three types of interferons. Abbreviations: JAK, Janus tyrosine kinase; STAT, signal transducer and activator of transcription; IRF, IFN regulatory factor; ISRE, IFN stimulated response element; GAS, IFN- $\lambda$ activated sequence.

type I IFNs, lambda IFNs are induced by viral infections and exhibit antiviral activity in cell culture. ${ }^{7,8}$ They demonstrate similarities in the expression pattern to type I IFNs. ${ }^{21}$ Furthermore, the IFN- $\lambda$ gene promoter shares sequence similarities with IFN promoters and is activated by the virusactivated transcription factors IRF3 and IRF7. ${ }^{22,23}$ Lauterbach et al recently showed that mouse $\mathrm{CD} 8 \alpha^{+}$dendritic cells (DCs) and their human counterparts BDCA3+ DCs are the major producers of IFN- $\lambda$ on stimulation with double-stranded RNA and TLR 3 ligand. ${ }^{24}$ This observation correlates with the findings from Kotenko et $\mathrm{al}^{7}$ and Sheppard et $\mathrm{al}^{8}$ as these authors showed that peripheral blood mononuclear cells produce high amounts of IFN- $\lambda$ on TLR 3 activation and stimulation with double stranded RNA. Thus, poly I:C appears to be an important adjuvant which induces the systemic production of IFN- $\lambda$. Additionally, IFN- $\lambda 3$ was shown to be an adjuvant of $\mathrm{T}$ cell responses in mice. ${ }^{24,25}$ Using a systematic screen Ank et al found that only few hematopoetic cells respond to IFN- $\lambda$. In particular, however, plasmacytoid dendritic cells were susceptible to stimulation with IFN- $\lambda .{ }^{26}$ Furthermore, in contrast to hematopoetic compartments, epithelial cells and keratinocytes were highly responsive to IFN- $\lambda$ treatment. ${ }^{26}$ Another group investigated the tissue specificity of IFN- $\lambda$ responsiveness. They showed that the expression of the IL-28R $\alpha$ and therefore the responsivness to type III cytokines is predominantly seen in stomach, intestine, lung, and skin cells. In particular, epithelial cells were highly responsive to type III IFNs. ${ }^{27}$ Within the liver, the receptor was found to be predominantly expressed on hepatocytes..$^{28}$ Recently, our group showed that IL-28A emerges as a key regulatory cytokine with pathogenic function in $\mathrm{T}$ cell-mediated liver injury. ${ }^{29}$ In addition, IFN- $\lambda$ has been shown to be expressed predominantly by dendritic cells on viral infection and may act directly on epithelial cells or hepatocytes.

\section{Genetics and biological effects of IFN- $\lambda$ : single-nucleotide polymorphisms of IFNs and their influence in diseases}

Three independent groups, namely Suppiah et al, ${ }^{30}$ Kotenko et $\mathrm{al}^{7}$ and Ge et $\mathrm{al}^{31}$ identified several singlenucleotide polymorphisms (SNPs) near the IL-28B gene region on human chromosome 19 by using genome-wide association studies (GWAS). They additionally showed that the presence of certain SNPs is associated with the response to pegylated IFN- $\alpha$ and ribavirin treatment in hepatitis $\mathrm{C}$ virus (HCV) -infected patients in Europe, ${ }^{30,31}$ Africa, ${ }^{31}$ and Asia. ${ }^{32}$ There is striking evidence that the frequency of the $\mathrm{CC}$ allele is associated with a higher rate of sustained virological response in $\mathrm{HCV}$-infected patients as compared to patients with the TT genotype. The $\mathrm{C}$ allele is quite common throughout eastern parts of Asia, but is less frequent in Africa. ${ }^{33}$ Thus, the IL-28B gene encoding for IFN- $\lambda 3$ has been identified as a key regulator of the immune response in $\mathrm{HCV}$ infection. The exact mechanisms of how SNPs in this gene affect the gene function is not well 
established, however. Another question is how these SNPs may affect the outcome of other chronic viral infections. On this question, Martin et al showed that the $\mathrm{C} / \mathrm{C}$ genotype of a specific IL-28B polymorphism (rs12979860) does not influence the outcome of hepatitis B virus or HIV infection. ${ }^{34} \mathrm{On}$ the other hand IL-28A (IFN- $\lambda 2$ ) and IL-29 (IFN- $\lambda 1$ ) were considered to inhibit HIV-1 infection in macrophages. ${ }^{35}$ However, coinfection of HCV and HIV increases the risk of death and the standard therapy with pegylated IFN- $\alpha$ and ribavarin has been found to induce significantly lower rates of sustained virological response. ${ }^{36}$ Recently, it was found that IFN- $\lambda 1$ has, besides its antiviral activity, a relevant role in immunomodulatory responses. Specifically, it was noted that this cytokine regulates the development of $\mathrm{T}$ helper (TH) 1 and TH2 cells. Additionally, Srinivas et al showed a markedly IFN- $\lambda 1$-dependent diminished IL-13 secretion in $\mathrm{T}$ cell cultures where IL-4 had been added. Therefore, IFN- $\lambda 1$ appears to be an inhibitor of human $\mathrm{TH} 2$ responses directed towards IL-13. ${ }^{37,38}$ Interestingly, there is a reciprocal control of IL-4 and IFN- $\lambda$ secretion. Megjugorac et al showed that IL-4 stimulation of monocytes leads to an elevated secretion of IL-1 receptor antagonist, which acts directly on plasmacytoid DCs (pDCs) to augment their IFN- $\lambda 1$ production and function. ${ }^{39}$ Accordingly, there is a mechanism in regulating IFN- $\lambda 1$ secretion and $\mathrm{pDC}$ function in which IFN- $\lambda 1$ emerges as a cytokine with an immunomodulatory role for TH2 generation. Furthermore, IFN- $\lambda$ leads to the generation of partially mature DCs with a tolerogenic phenotype. These DCs express high levels of major histocompatibility complex (MHC) I and MHC II but low levels of costimulatory molecules, and they have the ability to migrate to lymph nodes, once injected into immunodeficient mice. In addition, they showed the ability to induce mature DCs that where able to induce an IL-2-dependent proliferation of CD4+CD25+Foxp3+T cell population with a regulatory phenotype. ${ }^{40}$ Recently, it was found that the IL-28 cytokine expression was diminished in allergic asthma. Koltsida et al showed a novel role of IL-28 cytokines in TH1 generation and protection from allergic airway disease. Thus, beside high expression of IL-28R $\alpha$ on the gut epithelium the lung epithelium reveals expression of the IFN- $\lambda$ receptor and is therefore highly responsive to IFN- $\lambda$. The authors described an improvement of allergic airway disease after treating the mice with rIL-28A. Such treatment suppressed the TH2 and TH17 responses but induced local TH1 immune responses. ${ }^{41}$ Abrogation of endogenous IL-28 cytokine signaling by IL- $28 \mathrm{R} \alpha$ deficiency in mice aggravated experimental ovalbumin-mediated airway disease by increasing $\mathrm{TH} 2$ and $\mathrm{TH} 17$ responses as well as IgE levels.

\section{IFN- $\lambda$ and its antitumor activity}

In addition to its antiviral activity, type I IFN (IFN- $\alpha / \beta)$ has been found to inhibit tumor cell growth. This observation suggested the potential benefit of type I IFN therapy in several forms of cancer. However, type I IFN is a pleiotropic cytokine with many effects on various cell types due to the wide expression of its receptor complex. Accordingly, numerous side effects have been noted in patients treated with type I IFNs. ${ }^{42}$ The discovery of a new subgroup of IFNs (IFN- $\lambda$ ) with antiviral properties but more restricted receptor expression thus might represent a suitable alternative for cancer therapy. In fact, lambda IFNs revealed potent antitumor activity in murine models of cancer and have been proposed as novel tools for cancer treatment in patients. ${ }^{19,43,44}$ Due to the fact that the cellular receptor expression differs between IFN- $\alpha$ and IFN- $\lambda$, such therapy may result in fewer side effects. Indeed, the receptor for IFN- $\lambda$ is expressed only on a narrow range of cell types and the activity of IFN- $\lambda$ appears to be more tissue specific. ${ }^{28}$

First clinical trials with pegylated-IFN- $\lambda 1$ in patients with chronic HCV infection encouraged the idea that IFN- $\lambda$ is a promising therapeutic agent as an alternative to IFN- $\alpha{ }^{45,46}$ In contrast to the IFN- $\alpha$ receptor, the type III IFN receptor was mainly detected on tumor cells and many tumor cell lines. Studies in tumor cells lines have addressed the antiproliferative and antiapoptotic effects of lambda IFNs. For instance, Dumoutier et al showed that IFN- $\lambda 1$ inhibited growth of the murine BW5147 thymoma cell line but failed to inhibit the proliferation of the B lymphoma cell line Daudi. ${ }^{47}$ It was also found that IFN- $\lambda$ inhibits cell growth in the human glioblastoma LN319 cell line ${ }^{48}$ and additionally induces apoptosis in human neuroendocrine BON1 tumor cells, ${ }^{49}$ the human keratinocyte cell line $\mathrm{HaCaT}$, and the human fibrosarcoma $2 \mathrm{fTGH}$ cell line $\mathrm{f}^{50}$ as well as in murine melanoma and colon cancer cells. ${ }^{43}$ Thus, in contrast to IFN- $\alpha$, IFN- $\lambda$ could promote apoptosis in different cell lines and was more effective in inducing an antiproliferative effect associated with the induction of apoptosis. Interestingly, the combination of both IFNs augmented the effects on antiproliferative responses. As most solid tumors are of epithelial origin and as the IL-28R $\alpha$ is predominantly expressed on epithelial cells, it appears likely that type III IFNs have proapoptotic effects in cancer cells. Indeed, a proapoptotic effect of IFN- $\lambda$ in colorectal adenocarcinoma HT29 cells was noted that leads to caspase activation, 
externalization of phosphatidylserin, DNA fragmentation, and cell death. ${ }^{51}$ Another recent finding in colon 26 and murine melanoma B16 cell lines revealed a functional IFN- $\lambda$ receptor expression on the tumor cell surface. Transient transduction of IFN- $\lambda$ enhanced MHC I and surface Fas (CD95) expression and suppressed cell proliferation by induction of $\mathrm{p} 21^{\mathrm{Waf} / \mathrm{Cip} 1}$ and activation of caspase 3 and 7 activity. These findings indicated that lambda IFNs favor the induction of apoptosis in tumor cells accompanied with cell cycle arrest. ${ }^{43}$ However, the antitumor activity of IFN- $\lambda$ was mediated by tumor apoptosis and NK cell-mediated immunological tumor destruction. Another recent study confirmed these results in a different tumor cell line. In this series of studies, it was also discovered that the antitumor activity was partially dependent on IFN- $\gamma$ but independent of IL-12, IL-17, and IL-23. Concomitant systemic administration of IL-12 augmented IL-28-mediated antitumor activity in the presence or absence of IFN- $\gamma{ }^{44}$ In summary, virus-induced IL-28 expression by innate immune cells may be used for lysis of tumor cells and reduction of tumor burdens. ${ }^{52-54}$ Consistent with this concept, Wongthida et al identified that IL-28, induced by viral activation of innate immune cells, is a key modulator of antiviral and antitumor activity in B16 ova tumors. ${ }^{55}$ They showed also that the vesicular stromatitis virus activity depends on host CD8+ and natural killer cells. They clear the virus, and lambda IFNs have both direct and indirect antitumor activity. ${ }^{56,57}$ IFN- $\lambda 1$ also induced G1 phase arrest or apoptosis in oesophageal carcinoma cells. ${ }^{58}$ These data suggest that IFN- $\lambda 1$ might be a useful therapeutic agent for oesophageal carcinoma without marked damage of surrounding tissues.

In summary, these results illustrate that IFN- $\lambda$ has therapeutic properties for the clinical treatment of human malignancies and for suppression of tumor growth in vivo. As initial studies with recombinant lambda interferons in HCV infection showed relatively few side effects, such therapy might be both safe and effective. Controlled clinical trials addressing this concept are highly warranted.

\section{Conclusion}

The main role of IFNs is to inhibit viral replication in infected cells as well as to protect uninfected cells from viruses. The lambda IFNs IL-28A, IL-28B, and IL-29 are a new class of IFNs with potent antiviral and antitumor activities. These cytokines are produced in response to viral infections by various cell types including dendritic cells and macrophages. Although signaling events induced by lambda IFNs are similar to those of type I IFNs, lambda IFNs interact with a different, unique receptor complex that has a more restricted expression pattern compared with receptors for type I IFNs. For that reason type III IFNs have a higher tissue specificity than type I IFNs. Additionally, variations found in the IL-28B gene appear to influence the kinetics of viral response to therapy, as shown for patients with $\mathrm{HCV}$ infection bearing the $\mathrm{C} / \mathrm{C}$ genotype. Because of the tissue specificity of type III IFNs and the predominant expression of their receptor on epithelial cells, these cytokines appear to be a promising new approach for the treatment of several cancer forms in humans. Consistently, various studies have identified potent antitumor effects of lambda IFNs on cancer cells ex vivo or in animal models of cancer in vivo. Thus, lambda IFNs have opened new therapeutical strategies for viral infections and tumor immunity.

\section{Acknowledgment}

This review was supported by the Sonderforschungsbereich (SFB) 643 of the University Erlangen-Nürnberg, Germany.

\section{Disclosure}

The authors report no conflict of interest in relation to this work.

\section{References}

1. Isaacs A, Lindenmann J. Virus interference. I. The interferon. Proc $R$ Soc Lond B Biol Sci. 1957;147(927):258-267.

2. Muller U, Steinhoff U, Reis LF, et al. Functional role of type I and type II interferons in antiviral defense. Science. 1994;264(5167): 1918-1921.

3. Rasmussen SB, Sorensen LN, Malmgaard L, et al. Type I interferon production during herpes simplex virus infection is controlled by cell-type-specific viral recognition through Toll-like receptor 9, the mitochondrial antiviral signaling protein pathway, and novel recognition systems. J Virol. 2007;81(24):13315-13324.

4. Johansson C, Wetzel JD, He J, Mikacenic C, Dermody TS, Kelsall BL. Type I interferons produced by hematopoietic cells protect mice against lethal infection by mammalian reovirus. J Exp Med. 2007;204(6): 1349-1358.

5. Vilcek J. Fifty years of interferon research: aiming at a moving target. Immunity. 2006;25(3):343-348.

6. Borden EC, Sen GC, Uze G, et al. Interferons at age 50: past, current and future impact on biomedicine. Nat Rev Drug Discov. 2007;6(12) 975-990.

7. Kotenko SV, Gallagher G, Baurin VV, et al. IFN-lambdas mediate antiviral protection through a distinct class II cytokine receptor complex. Nat Immunol. 2003;4(1):69-77.

8. Sheppard P, Kindsvogel W, Xu W, et al. IL-28, IL-29 and their class II cytokine receptor IL-28R. Nat Immunol. 2003;4(1):63-68.

9. Li X, Leung S, Kerr IM, Stark GR. Functional subdomains of STAT2 required for preassociation with the alpha interferon receptor and for signaling. Mol Cell Biol. 1997;17(4):2048-2056.

10. Li X, Leung S, Qureshi S, Darnell JE Jr, Stark GR. Formation of STAT1-STAT2 heterodimers and their role in the activation of IRF-1 gene transcription by interferon-alpha. J Biol Chem. 1996; 271(10):5790-5794 
11. Decker T, Muller M, Stockinger S. The yin and yang of type I interferon activity in bacterial infection. Nat Rev Immunol. 2005;5(9):675-687.

12. Briscoe J, Rogers NC, Witthuhn BA, et al. Kinase-negative mutants of JAK1 can sustain interferon-gamma-inducible gene expression but not an antiviral state. EMBO J. 1996;15(4):799-809.

13. Greenlund AC, Morales MO, Viviano BL, Yan H, Krolewski J, Schreiber RD. Stat recruitment by tyrosine-phosphorylated cytokine receptors: an ordered reversible affinity-driven process. Immunity. 1995;2(6):677-687.

14. Darnell JE Jr, Kerr IM, Stark GR. Jak-STAT pathways and transcriptional activation in response to IFNs and other extracellular signaling proteins. Science. 1994;264(5164):1415-1421.

15. Schindler C, Darnell JE Jr. Transcriptional responses to polypeptide ligands: the JAK-STAT pathway. Annu Rev Biochem. 1995;64: 621-651.

16. Ramana CV, Chatterjee-Kishore M, Nguyen H, Stark GR. Complex roles of Stat1 in regulating gene expression. Oncogene. 2000; 19(21):2619-2627.

17. Stark GR, Kerr IM, Williams BR, Silverman RH, Schreiber RD. How cells respond to interferons. Annu Rev Biochem. 1998;67:227-264.

18. Uze G, Monneron D. IL-28 and IL-29: newcomers to the interferon family. Biochimie. 2007;89(6-7):729-734.

19. Lasfar A, Lewis-Antes A, Smirnov SV, et al. Characterization of the mouse IFN-lambda ligand-receptor system: IFN-lambdas exhibit antitumor activity against B16 melanoma. Cancer Res. 2006;66(8): 4468-4477.

20. Akira S, Uematsu S, Takeuchi O. Pathogen recognition and innate immunity. Cell. 2006;124(4):783-801.

21. Onoguchi K, Yoneyama M, Takemura A, et al. Viral infections activate types I and III interferon genes through a common mechanism. J Biol Chem. 2007;282(10):7576-7581.

22. Mogensen TH, Paludan SR. Reading the viral signature by Toll-like receptors and other pattern recognition receptors. $J$ Mol Med. 2005; 83(3): 180-192.

23. Osterlund PI, Pietila TE, Veckman V, Kotenko SV, Julkunen I. IFN regulatory factor family members differentially regulate the expression of type III IFN (IFN-lambda) genes. J Immunol. 2007; 179(6):3434-3442.

24. Lauterbach H, Bathke B, Gilles S, et al. Mouse CD8alpha+ DCs and human BDCA3+ DCs are major producers of IFN-lambda in response to poly IC. $J$ Exp Med. 2010;207(12):2703-2717.

25. Morrow MP, Yan J, Pankhong P, et al. Unique Th1/Th2 phenotypes induced during priming and memory phases by use of interleukin- 12 (IL-12) or IL-28B vaccine adjuvants in rhesus macaques. Clin Vaccine Immunol. 2010;17(10):1493-1499.

26. Ank N, Iversen MB, Bartholdy C, et al. An important role for type III interferon (IFN-lambda/IL-28) in TLR-induced antiviral activity. J Immunol. 2008;180(4):2474-2485.

27. Sommereyns C, Paul S, Staeheli P, Michiels T. IFN-lambda (IFNlambda) is expressed in a tissue-dependent fashion and primarily acts on epithelial cells in vivo. PLoS Pathog. 2008;4(3):e1000017.

28. Doyle SE, Schreckhise H, Khuu-Duong K, et al. Interleukin-29 uses a type 1 interferon-like program to promote antiviral responses in human hepatocytes. Hepatology. 2006;44(4):896-906.

29. Siebler J, Wirtz S, Weigmann B, et al. IL-28A is a key regulator of T-cell-mediated liver injury via the T-box transcription factor T-bet. Gastroenterology. 2007;132(1):358-371.

30. Suppiah V, Moldovan M, Ahlenstiel G, et al. IL28B is associated with response to chronic hepatitis $\mathrm{C}$ interferon-alpha and ribavirin therapy. Nat Genet. 2009;41(10):1100-1104.

31. Ge D, Fellay J, Thompson AJ, et al. Genetic variation in IL28B predicts hepatitis C treatment-induced viral clearance. Nature. 2009; 461(7262):399-401.

32. Tanaka Y, Nishida N, Sugiyama M, et al. Genome-wide association of IL28B with response to pegylated interferon-alpha and ribavirin therapy for chronic hepatitis C. Nat Genet. 2009;41(10):1105-1109.
33. Thomas DL, Thio CL, Martin MP, et al. Genetic variation in IL28B and spontaneous clearance of hepatitis C virus. Nature. 2009;461(7265): 798-801.

34. Martin MP, Qi Y, Goedert JJ, et al. IL28B polymorphism does not determine outcomes of hepatitis B virus or HIV infection. J Infect Dis. Dec 1 2010;202(11):1749-1753.

35. Hou W, Wang X, Ye L, et al. Lambda interferon inhibits human immunodeficiency virus type 1 infection of macrophages. JVirol. 2009; 83(8):3834-3842.

36. Aparicio E, Parera M, Franco S, et al. IL28B SNP rs8099917 is strongly associated with pegylated interferon-alpha and ribavirin therapy treatment failure in $\mathrm{HCV} / \mathrm{HIV}-1$ coinfected patients. PLoS One. 2010;5(10):e13771.

37. Srinivas S, Dai J, Eskdale J, Gallagher GE, Megjugorac NJ, Gallagher G. Interferon-lambda1 (interleukin-29) preferentially down-regulates interleukin-13 over other T helper type 2 cytokine responses in vitro. Immunology. 2008;125(4):492-502.

38. Jordan WJ, Eskdale J, Srinivas S, et al. Human interferon lambda-1 (IFN-lambda1/IL-29) modulates the Th1/Th2 response. Genes Immun. 2007;8(3):254-261.

39. Megjugorac NJ, Gallagher GE, Gallagher G. IL-4 enhances IFNlambda1 (IL-29) production by plasmacytoid DCs via monocyte secretion of IL-1Ra. Blood. 2010;115(21):4185-4190.

40. Mennechet FJ, Uze G. Interferon-lambda-treated dendritic cells specifically induce proliferation of FOXP3-expressing suppressor T cells. Blood. 2006;107(11):4417-4423.

41. Koltsida O, Hausding M, Stavropoulos A, et al. IL-28A (IFN-lambda2) modulates lung DC function to promote Th1 immune skewing and suppress allergic airway disease. EMBO Mol Med. 2011;3(6): 348-361.

42. Pestka S, Krause CD, Walter MR. Interferons, interferon-like cytokines, and their receptors. Immunol Rev. 2004;202:8-32.

43. Sato A, Ohtsuki M, Hata M, Kobayashi E, Murakami T. Antitumor activity of IFN-lambda in murine tumor models. J Immunol. 2006;176(12):7686-7694.

44. Numasaki M, Tagawa M, Iwata F, et al. IL-28 elicits antitumor responses against murine fibrosarcoma. J Immunol. 2007;178(8):5086-5098.

45. Muir AJ, Shiffman ML, Zaman A, et al. Phase 1b study of pegylated interferon lambda 1 with or without ribavirin in patients with chronic genotype 1 hepatitis C virus infection. Hepatology. 2010;52(3): 822-832.

46. Miller DM, Klucher KM, Freeman JA, Hausman DF, Fontana D, Williams DE. Interferon lambda as a potential new therapeutic for hepatitis C. Ann NY Acad Sci. 2009;1182:80-87.

47. Dumoutier L, Tounsi A, Michiels T, Sommereyns C, Kotenko SV, Renauld JC. Role of the interleukin (IL)-28 receptor tyrosine residues for antiviral and antiproliferative activity of IL-29/interferonlambda 1: similarities with type I interferon signaling. $J$ Biol Chem. 2004:279(31):32269-32274.

48. Meager A, Visvalingam K, Dilger P, Bryan D, Wadhwa M. Biological activity of interleukins-28 and -29: comparison with type I interferons. Cytokine. 2005;31(2):109-118.

49. Zitzmann K, Brand S, Baehs S, et al. Novel interferon-lambdas induce antiproliferative effects in neuroendocrine tumor cells. Biochem Biophys Res Commun. 2006;344(4):1334-1341.

50. Maher SG, Sheikh F, Scarzello AJ, et al. IFNalpha and IFNlambda differ in their antiproliferative effects and duration of JAK/STAT signaling activity. Cancer Biol Ther. 2008;7(7):1109-1115.

51. Li W, Lewis-Antes A, Huang J, Balan M, Kotenko SV. Regulation of apoptosis by type III interferons. Cell Prolif. 2008;41(6):960-979.

52. Kirn D. Oncolytic virotherapy for cancer with the adenovirus d11520 (Onyx-015): results of phase I and II trials. Expert Opin Biol Ther. 2001;1(3):525-538.

53. Kirn D, Martuza RL, Zwiebel J. Replication-selective virotherapy for cancer: biological principles, risk management and future directions. Nat Med. 2001;7(7):781-787. 
54. Parato KA, Senger D, Forsyth PA, Bell JC. Recent progress in the battle between oncolytic viruses and tumours. Nat Rev Cancer. 2005;5(12):965-976.

55. Wongthida P, Diaz RM, Galivo F, et al. Type III IFN interleukin-28 mediates the antitumor efficacy of oncolytic virus VSV in immune-competent mouse models of cancer. Cancer Res. 2010;70(11): 4539-4549.

56. Galivo F, Diaz RM, Wongthida P, et al. Single-cycle viral gene expression, rather than progressive replication and oncolysis, is required for VSV therapy of B16 melanoma. Gene Ther. 2010;17(2):158-170.
57. Prestwich RJ, Errington F, Diaz RM, et al. The case of oncolytic viruses versus the immune system: waiting on the judgment of Solomon. Hum Gene Ther. 2009;20(10):1119-1132.

58. Li Q, Kawamura K, Ma G, et al. Interferon-lambda induces G1 phase arrest or apoptosis in oesophageal carcinoma cells and produces anti-tumour effects in combination with anti-cancer agents. Eur $J$ Cancer. 2010;46(1):180-190.

International Journal of Interferon, Cytokine and Mediator Research

\section{Publish your work in this journal}

The International Journal of Interferon, Cytokine and Mediator Research is an international, peer-reviewed, open-access, online journal. The focus of the journal is to publish original research, reports, editorials, reviews and commentaries on all aspects of interferon, cytokine and mediators of inflammation from labora- tory science to therapeutic indications and clinical studies. The manuscript management system is completely online and includes a very quick and fair peer-review system, which is all easy to use. Visit http://www.dovepress.com/testimonials.php to read real quotes from published authors.

Submit your manuscript here: http://www.dovepress.com/international-journal-of-interferon-cytokine-and-mediator-research-journal 